\title{
O Pífano de Bambu: o Músico Artífice de seu Instrumento
}

The bamboo flute - Pifano: a craftsman musician who makes this instrument of special tunings

SASAOKA, Silvia; Doutoranda; UNESP/FAAC/PPG Design/Bauru

silvia.sasaoka@gmail.com

PEREIRA, Marco A. R.; Prof. Dr.; UNESP/FEB/FAAC/PPG Design/Bauru

pereira@feb.unesp.br

SANTOS, Gabriel F.; Doutorando; UNESP/FAAC/PPG Design/Bauru

gabrielfernandes.cereja@gmail.com

\section{Resumo}

Este estudo analisou o trabalho artesanal de flautas de pífanos de bambu de afinações especiais, produzidos por um músico artífice. O objetivo desta investigação foi observar o caminho que o músico percorre na construção de sentidos do seu fazer, sua relação com a matéria prima, o seu processo inventivo e o modo de produção do pífano de bambu. O exercício deste olhar, resiste ao contexto de produção atual do artesanato brasileiro, muito mais focado na prática econômica do que cultural e artística. Os métodos adotados foram a revisão bibliográfica e aplicação de entrevista com o músico artífice. O procedimento adotado pelo músico artífice para realização de seu instrumento caracteriza-se como uma prática de design, por meio da sistematização da forma de produção de um saber empírico e tradicional a fim de disseminar o conhecimento e preservar uma cultura musical.

Palavras Chave: design; artesanato; pífano de bambu.

\section{Abstract}

This study assessed the craft work of the bamboo flute -Pifano- by an artisan musician who makes this instrument of special tunings. The purpose of this research is to observe the path, the musician takes in the construction of the senses of his making, its relation with a raw material as bamboo, the innovation and the way of production of the bamboo pifano. Under a critical eye, it resists to a current Brazilian craft production context, more focused on economic practice than cultural and artistic issue. A methodology adopted is based on a bibliographical review and direct interviews with the musician and pifano artisan. The procedure adopted by the artisan musician to conceive his instrument can be characterized as a design practice, through the systematization of production of empirical and traditional knowledge in order to disseminate the knowledge and preserve a musical culture.

Keywords: design; crafts; bamboo pífano. 


\section{Introdução}

Este trabalho está ancorado na visão de Margolin (2013), que compreende o design como atividade praticada por pessoas que, sob diferentes condições produziram coisas para atender suas necessidades diárias em todas as partes do mundo. $O$ design é uma ferramenta fundamental capaz de promover mudanças e solucionar necessidades. Integra diversas áreas de conhecimento atuando no domínio dos processos criativos, nos modos de produção e de comunicação. No contexto da sociedade complexa contemporânea, o design extrapola a função de desenhar, projetar, planejar e produzir, se apoiando na sensibilidade humana e usando estratégias de abordagens sistêmicas para a construção de valores e significados. Dessa forma, o design pode ser compreendido e praticado como um recurso didático para o ensino e aprendizagem de artesãos.

O mercado do artesanato de bambu cresce progressivamente no mundo todo, no entanto, o cenário brasileiro apresenta desafios dicotômicos para seus produtores. Por um lado, há pouca procura por produtos de bambu decorrente da falta de conhecimento deste material pelo público consumidor e, por outro lado, o artesanato nacional sofre a concorrência do alto nível de competência do artesanato de produção asiática. Assim, a presente investigação teve como premissa refletir sobre os paradigmas estéticos, técnicos e culturais diferenciadores que poderiam contribuir para o processo de criação do artesanato de bambu.

Na perspectiva da fruição estética, a diferença é atribuída por valores externos aos objetos criados pelo artesão. Estes valores são alicerçados em referências culturais e pessoais, no acesso a informações e no repertório de conhecimentos daquele que produz e daquele que aprecia. Contudo, os elementos intrínsecos de julgamento do objeto/produto tais como o material utilizado, o tratamento da matéria-prima e as técnicas desenvolvidas, também são portadores de valor e reconhecimento de qualidade por si mesmos.

O material bambu contribui para esta reflexão e prática por sua presença secular na cultura humana da subsistência na construção de abrigos, na confecção de instrumentos musicais e utilitários até o desenvolvimento de produtos industrializados. A cultura do bambu ocupa importante papel na economia rural nos países da Ásia tropical e subtropical há centenas de anos (HSUING, 1988 apud PEREIRA \& BERALDO, 2008). Estima-se a existência de quatro mil diferentes usos do bambu na China. No Brasil, o bambu é empregue, principalmente, na produção de papel, na construção, no artesanato de cestarias, nas varas de pescar, no mobiliário, em utensílios, na produção de brotos e em alguns instrumentos musicais.

Esta investigação apresenta a estruturação básica de uma ideia de valor da qualidade do trabalho artesanal de bambu na sua inventividade e, especialmente, na dimensão estética deste material e sua prática. O objeto estudado foi o músico José Cláudio Lino, que é o artífice de seu próprio instrumento - o pífano, inserido no contexto cultural brasileiro contemporâneo. O objetivo da investigação foi observar o músico e artífice na sua relação com os usos e a natureza deste objeto criado por ele, o seu modo de produção e a sua experiência na busca de uma qualidade sonora, da forma e função do instrumento, específicas do bambu.

Este estudo qualitativo foi realizado por meio de uma pesquisa de campo com observação in loco na residência e oficina do músico e construtor de pífanos. A residência e oficina do músico investigado estão sediadas na cidade de Botucatu e a área de coleta de bambus que este faz para sua produção de pífanos, está localizada na zona rural, ao sul da mesma cidade do interior paulista. Para a condução das investigações foram adotados os métodos de revisão bibliográfica e entrevista 
aberta com o músico e artífice. A partir desta vivência, foi possível a coleta de dados com o uso de registros audiovisuais, sendo analisados tanto o processo desenvolvido pelo músico e artífice para produção de pífanos de bambus quanto o próprio instrumento musical concebido. O que permitiu a construção de uma compreensão do fenômeno estético e o caminho que o músico e artífice percorre na construção dos sentidos do seu fazer artesanal. E uma vez sistematizada a forma de produção de um saber empírico e tradicional, tornam-se tangíveis tanto a sua disseminação quanto a sua preservação.

Para os fins específicos desta pesquisa, no intuito de demarcar um diferencial preciso, entre as duas formas de fazer manual aqui tratada, identifica-se o artesão de bambu, como um criador e produtor de um objeto artístico ou utilitário, cuja atividade profissional garante sua fonte de renda. E o músico artífice, que também emprega suas habilidades técnicas e manuais na materialização de sua ideia ou projeto, como meio para viabilizar um instrumento para atingir uma qualidade musicalfruto de uma estética. Assim, este permanece sendo músico e não artesão.

\section{O Objeto de Estudo - O Músico, Artífice de seu Instrumento Musical}

Neste estudo foi observado um músico que se tornou artífice de seu próprio instrumento, José Cláudio Lino, nascido em Campinas no ano de 1952. Formou-se em engenharia mecânica pela Universidade de São Paulo em São Carlos, mas logo decidiu que seria músico. Entrou no Conservatório Musical Dr. Carlos de Campos, em Tatuí no interior paulista e desde então passou a tocar profissionalmente saxofone, flauta e pífano. Lino é compositor, arranjador e professor de música há 40 anos, além de dirigir orquestras de jovens em projetos sociais na cidade de Botucatu.

Lino iniciou sua pesquisa entre os anos 2007 e 2008, na ocasião em que participou de uma oficina em sua cidade com a banda de pífanos "Flautim Matuá" de Campinas. Mais recentemente, Lino foi contemplado em dezembro de 2017, com o prêmio "Mestres da Cultura Popular" 2017, reconhecimento promovido pelo Ministério da Cultura. Neste prêmio, Lino foi selecionado entre 200 mestres dos 1600 inscritos, devido ao seu trabalho realizado com: oficinas de construção de pífanos; publicação do Método Prático de Pífanos de Bambu (2008); cursos ministrados de pífanos em projetos sociais e em escolas; o trabalho de composição e arranjo para a Banda Bambu que resultou na produção do CD Pife Camaleão.

A ideia do músico que é o próprio artífice de seu instrumento está ancorada em Sennett (2009), que defende que todas as pessoas têm a vocação de se tornarem bons artífices, quando dedicadas ao trabalho, desenvolvendo suas habilidades técnicas e manuais. O mesmo autor continua dizendo que, uma vez engajadas, as pessoas podem vir a alcançar sua autonomia, a satisfação com o saber fazer e a realização pessoal. Nesse sentido, o autor conclui que todos "[...] podemos alcançar uma vida material mais humana, se pelo menos entendermos como são feitas as coisas" (SENNETT, Op. cit., p. 18).

É escasso o número de estudos acadêmicos sobre o pífano, e especialmente sob o foco das qualidades morfológicas, botânicas e tecnológicas do bambu adequadas para pífanos (MAGALHÃES, 2009). A partir da participação em oficinas, Lino experimentou diversas formas de produzir pífanos até chegar num ponto de aprimoramento que lhe permitiu desenvolver tal instrumento com o bambu colhido em sua cidade. Como resultado, Lino alcançou uma linha especial de pífanos com afinação única, que os diferenciavam da afinação em escala maior própria do pífano nordestino.

A motivação inicial para essa alteração incremental no processo de produção do pífano de 
bambu ocorreu quando lecionava música na Escola Waldorf Aitiara, localizada no Bairro Demétria, área rural na zona sul de Botucatu. No local encontram-se caminhos cobertos de bambuzais. A metodologia Waldorf estimula os alunos à construção de sua aprendizagem por meio de práticas artísticas e musicais. Como professor de música, Lino quis introduzir o pífano na banda de alunos que tocavam diferentes instrumentos tais como acordeom, piano, flauta transversal e violão, entre outros. Criou a Banda Bambu formada a partir de curso ministrado na escola, e que atualmente conta com seis membros que se apresentam profissionalmente. Foi necessário efetuar ajustes na afinação do pífano tradicional que possui um sistema de afinação, escala musical e sonoridade próprias, diferente do sistema ocidental e erudito. Neste processo, Lino foi se tornando um artífice enquanto desenvolvia um novo pífano, cujo bocal se assemelha à flauta transversal e possui uma afinação particular, alcançada com a modificação do diâmetro dos orifícios no bambu, em busca de sonoridades e tons musicais específicos.

A afinação é tópico central para todo instrumentista ou cantor em sua prática musical (FREIRE, 2016). O mesmo autor explica que "a subjetividade do músico manifesta-se nos pequenos ajustes nas frequências das notas no seu instrumento, que precisam ser modificadas para entrar em concordância com as frequências das notas de outros instrumentos" (FREIRE, Op. cit., p. 4). No processo de produção do pífano feito por Lino, por meio de experimentações, perfurando o bambu em diferentes tamanhos, a afinação do pífano ficou compatível com a do afinador eletrônico - que hoje substitui o antigo diapasão. Lino explica que o som dos pífanos pode variar porque é da natureza do bambu possuir diferentes espessuras e diâmetros, o que dá uma sonoridade particular a cada instrumento. Deste modo, os pífanos terão sempre sonoridades próprias, assim diferenciadas por não haver bambus idênticos.

\section{O Objeto Artesanal e Musical - O Pífano Tradicional}

O pífano é uma flauta transversal feita de bambu, taquara ou taboca, como a planta é conhecida popularmente no Nordeste. Este material é encontrado na própria natureza local, não exigindo processamentos complexos para confecção do pífano, fator que explica a presença deste instrumento em muitas formações musicais (MAGALHÃES, 2009). Entre os anos de 1500-1600, o pífano foi introduzido no Brasil provavelmente pelos jesuítas e militares portugueses e chegou aos sertões nordestinos levados por populações miscigenadas indígenas (MAGALHÃES, 2010).

O pífano tradicional nordestino está ligado ao contexto da cultura musical de vivência empírica e oral. A criação musical é entendida como invenção e não pode ser inserida nos modelos de composição e autoria de conhecimento técnico e formal (VELHA, 2008). Portanto, os músicos não usam partitura para tocar. O pífano está presente em quase todos os estados nordestinos, por meio da presença de inúmeras bandas que se apresentam historicamente tocando em praças públicas, procissões, novenas, carnavais, casamentos e festas. É comum encontrar nessas formações musicais o pífano aos pares, acompanhado de zabumba, caixa surdo e prato. $\mathrm{Na}$ formação dessas bandas não há instrumentos harmônicos como violão e piano ou outros.

O pífano tradicional é constituído de sete orifícios, um para soprar e seis para dedilhar, conforme ilustra a Figura 1. Algumas flautas de bambu são tampadas com a própria estrutura morfológica do bambu, mais especificamente o diafragma do colmo. 
Figura 1 - Planta de um pífano tradicional de bambu de Geraldo Nazário.

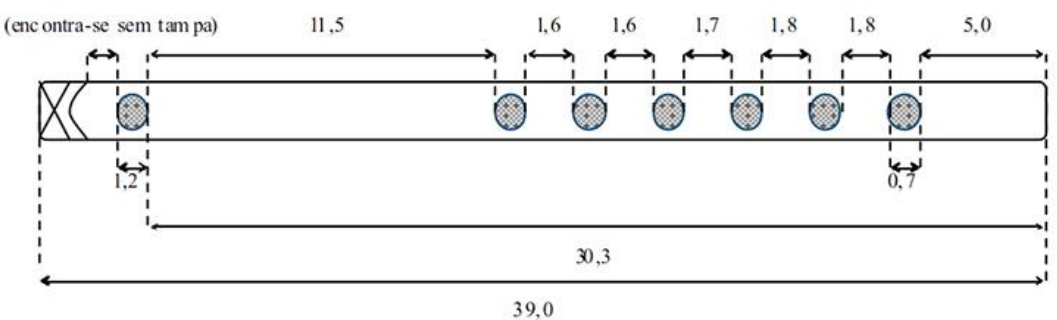

$\varnothing_{1,85 \mathrm{~cm}}$

4. Fabricação: César [?]

A cervo: Jadir Canela

Mat erial: Bambu

Cor: Tom natural de bam bu

$\mathrm{N}$ ota fundament al: sib3 $\downarrow$

Observações: Possui entalhes omamentais, anéis de metal nas duas extremidades, crucifixo preso em uma delas. Tampado pelo próprio nó do bambu. Flauta ut ilizada atualmente pela Caixa de Assovio.

Fonte: Magalhães (2009, p. 129).

Observa-se que os orifícios têm o mesmo diâmetro mudando apenas a distância entre eles. Além do timbre, outra característica importante deste instrumento de bambu é seu peso, que permite agilidade e deslocamento físico. Essa particularidade veio de sua origem histórica de acompanhamento musical em bandas militares que atravessavam grandes distâncias por terra ou por mar (MAGALHÃES, 2009). A Figura 2 apresenta o tradicional músico, compositor e pifeiro João Alfredo Marques dos Santos mais conhecido como João do Pife, originalmente de Caruaru, Pernambuco.

Figura 2 - João do Pife de Caruaru dedilha um pífano tradicional.

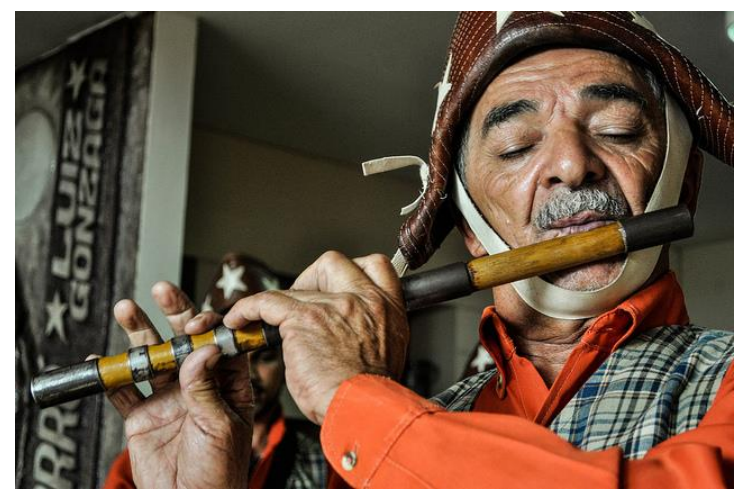

Fonte: Revista Algomais (2017).

Nascido em 1943, João do Pife aprendeu a tocar e produzir pífanos de bambu com o pai na infância, enquanto trabalhava na lavoura, e mantém ainda hoje a Banda de Pífanos Dois Irmãos criada por seu pai em 1928. Atualmente é mestre, ensina como construir o instrumento baseado em medidas padrão, provavelmente herdados de seus ancestrais, e a tocar suas músicas. Esta 
prática é orientada por uma cultura oral aos seus discípulos, em convivência direta, em que pode expressar seu universo e valores musicais. No entanto, essa experiência pode ser limitadora na difusão deste saber para o público mais amplo.

Lino transcreveu diversas músicas de João do Pife entre outros pifeiros para partituras. Devido à falta de literatura musical sobre o instrumento, ele elaborou em 2008 o Método Prático de Pífanos de Bambu, aproveitando seus conhecimentos didáticos com os instrumentos de sopro. Os exercícios estão escritos em partitura, gravados com o pífano em CD e podem ser usados como treinamento auditivo. Apresenta repertório de vários gêneros musicais.

\section{O Material Bambu na Confecção de Pífanos de Diversas Tonalidades}

O bambu é uma planta gramínea que pertence à família Graminae e subfamília Bambusoideae. São estimadas, aproximadamente, 1300 espécies e 50 gêneros, sendo que no Brasil, o número de bambus nativos é de 232 espécies (PEREIRA \& BERALDO, 2008). Em quase todos os continentes do planeta, exceto na Europa e Antártida, há ocorrências naturais de bambus nativos (KELCHNER, 2013), como pode ser visualizado na Figura 3.

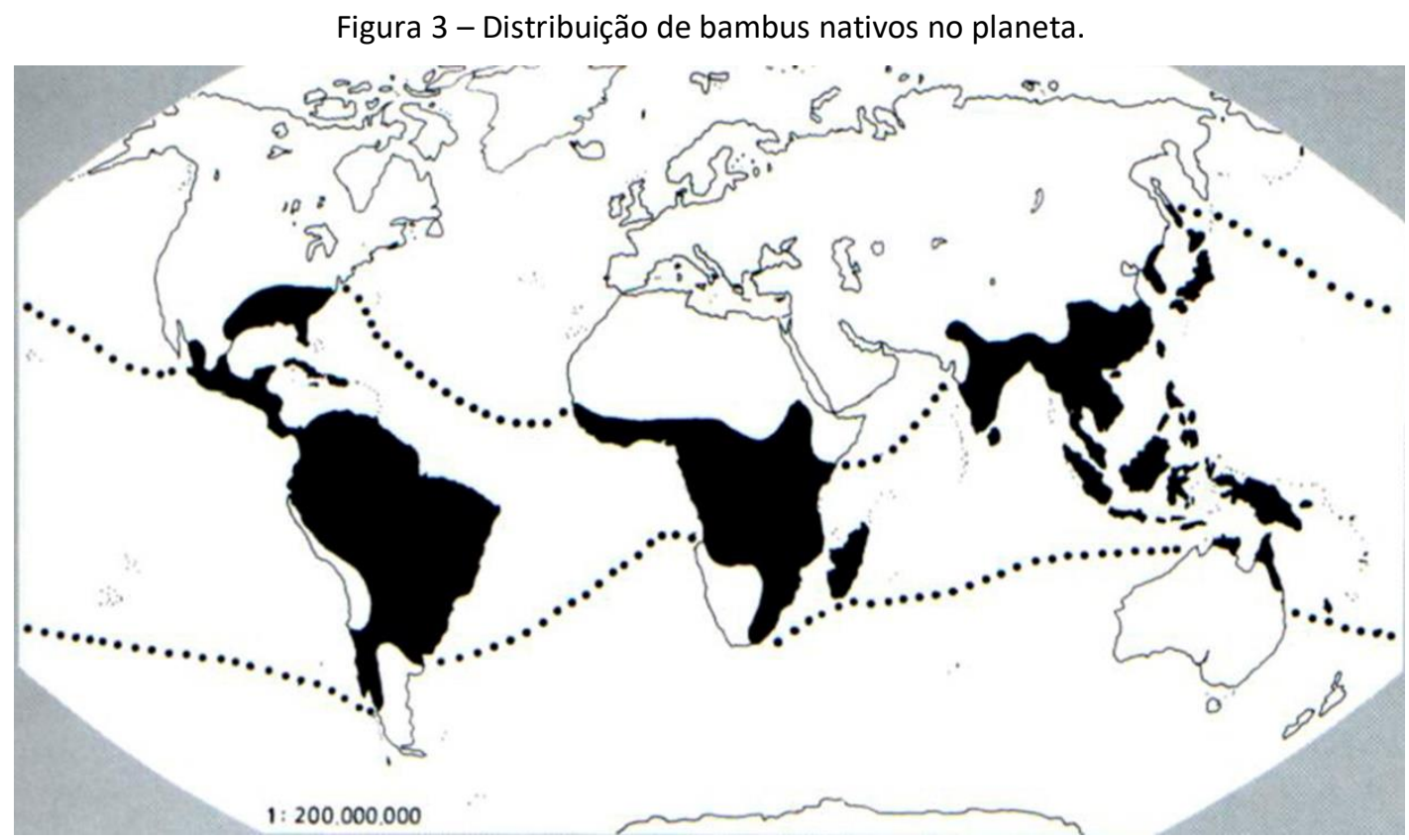

Fonte: Recht \& Wetterwald (1992) apud Pereira \& Beraldo (2008).

Nas regiões tropicais e subtropicais, especialmente nos países asiáticos, o bambu é um recurso natural básico que desempenha um importante papel no cotidiano das pessoas, influenciando nas dimensões econômica e cultural, pois está disponível localmente e é facilmente beneficiado, o que propicia um uso amplo, como nas produções de habitações, mobiliários e artesanatos (PEREIRA \& BARATA, 2008; WANG \& REN, 2009; HUNG \& WU, 2010). O Brasil se destaca entre os países da América pela existência da maior diversidade de espécies nativas de bambu, sendo estimadas a concentração na ordem de 26 \% na área da floresta amazônica, 65 \% na mata atlântica e $9 \%$ na região do cerrado (FILGUEIRAS \& GONÇALVES, 2004). Em quase todas as regiões do país é possível cultivar o bambu, exceto em territórios pantanosos assim como regiões castigadas pelas secas como no bioma da caatinga (GRECO, PINTO \& CAETANO, 2015). 
Os colmos de bambus possuem uma forma tronco cônica orgânica e, na maioria das espécies, ocos, exceto os colmos de espécies do gênero Chusquea, que são praticamente maciços (RAMOS, 2015). A estrutura básica do colmo de bambu dispõe de uma segmentação de internós ocos, na maior parte das espécies, estando separados por diafragmas na sua parte interna e que na parte externa são vistos como nós, conferindo a este vegetal, flexibilidade, leveza e elevada resistência mecânica (PEREIRA \& BERALDO, 2008). Dos nós brotam ramos laterais aéreos que carregam as folhas dos colmos. Tais características podem apresentar adaptações nas centenas de espécies existentes, configurando bambus de portes grande, médio e pequeno. A Figura 4 permite uma melhor visualização da estrutura básica de um colmo de bambu.

Figura 4. Seção da estrutura básica do colmo de bambu.

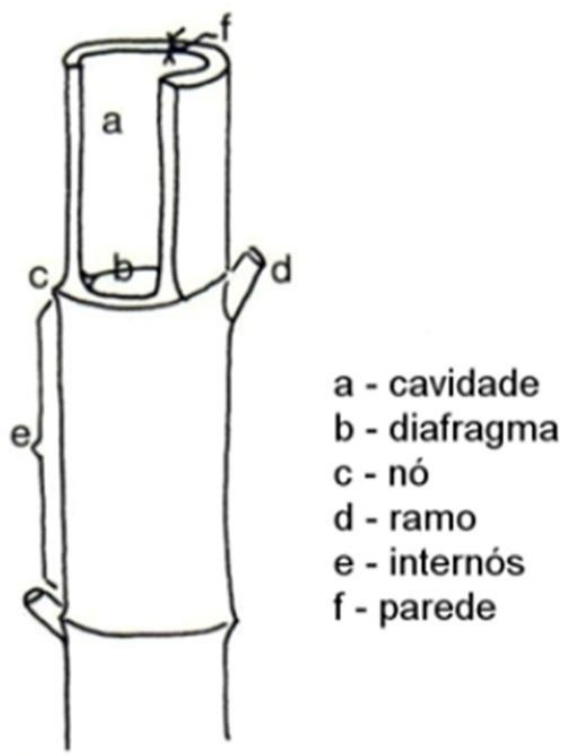

Fonte: Janssen (1988) apud Pereira \& Beraldo (2008).

No Brasil, o uso do bambu vai de encontro com a lei federal no. Lei 12.484, que foi promulgada no ano de 2011 pelos ministérios da Ciência e Tecnologia, visando se estabelecer como uma política de incentivo à cultura do bambu no país e promover o crescimento sustentável. Os pífanos tradicionais provêm da região do Nordeste, onde prevalecem os bambus nativos mais popularmente reconhecidos como taquara ou taboca.

\subsection{A Colheita do Bambu}

Tanto o pífano tradicional quanto os que Lino elabora, utilizam apenas uma parte do colmo de um bambu maduro, mais especificamente uma parte do internó de um colmo retilíneo. Alguns pífanos tem uma extremidade fechada por um diafragma e a outra aberta. Pode-se também extrair os dois diafragmas e utilizar uma rolha para fechar uma das extremidades. A área de colheita está localizada na estrada interna do Bairro Demétria em Botucatu. Tratando-se de um bambu nativo, a espécie que predomina nesse local é desconhecida tanto para o artífice quanto para os autores deste estudo, Figura 5. 
Figura 5 - Touceiras de bambus na estrada do Bairro Demétria, Botucatu.

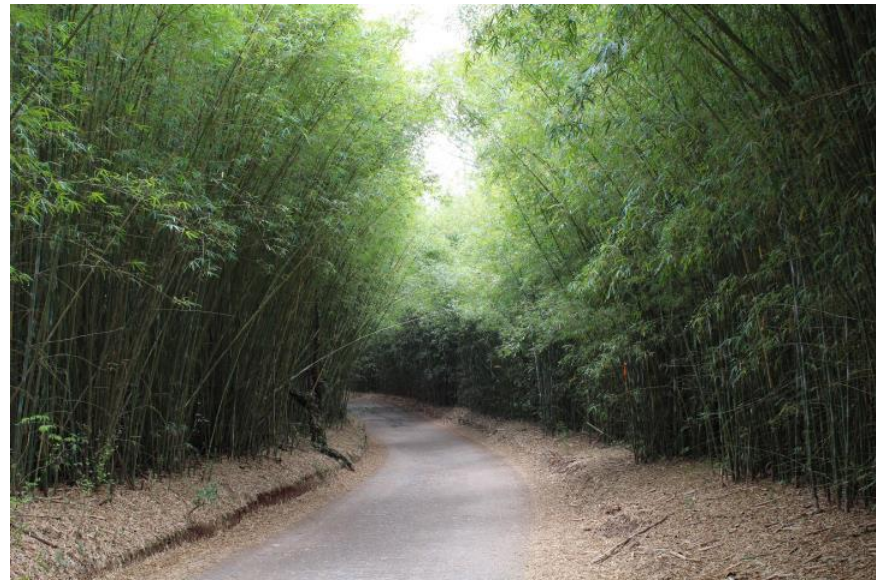

Fonte: autores.

O bambu utilizado por Lino possui médio porte, atingindo cerca de doze metros de altura. $\mathrm{O}$ diâmetro dos colmos atinge no máximo cerca de cinco centímetros e a espessura da parede é fina, comumente encontrada abaixo de 1 centímetro em sua parte mais espessa.

\subsection{A Técnica do Corte dos Internós}

Lino explica que os colmos mais adequados para seus instrumentos têm diâmetros que variam entre 1,5 e 2,2 centímetros. A espessura da parede deve ter no máximo três milímetros. Para melhor entendimento da influência dos diâmetros dos colmos de bambus na tonalidade do som produzido pelo pífano produzido, o músico e artífice investigado neste estudo, organizou seus conhecimentos em um quadro, cuja transcrição é mostrada no Quadro 1.

Quadro 1 - Relação entre diâmetros e tonalidades correspondentes.

\begin{tabular}{llllllll}
\hline Tonalidades & $\mathrm{C}$ & $\mathrm{Bb}$ & $\mathrm{A}$ & $\mathrm{G}$ & $\mathrm{F}$ & $\mathrm{E}$ & $\mathrm{D}$ \\
& (Dó) & (Si bemol) & $\begin{array}{l}\text { (Lá) } \\
\text { (Sol) }\end{array}$ & $\begin{array}{l}\text { (Fá) } \\
\text { (Mi) }\end{array}$ & \\
\hline Diâmetro Interno em mm & $14-15$ & $15-16$ & $16-17$ & $18-20$ & $19-20$ & $19-21$ & $20-22$
\end{tabular}

Fonte: adaptado de José Cláudio Lino.

E quanto maior for o comprimento dos internós mais grave será a tonalidade do instrumento. E para atingir os tons mais agudos, usam-se os internós menores. A parte utilizada dos colmos de bambus para a produção dos pífanos é a parte central, podendo render de quatro a cinco pífanos. Na última colheita que Lino realizou, no mês de novembro de 2017, foram colhidos aproximadamente 25 colmos, material suficiente para cerca de 100 pífanos. Na oficina do músico, os colmos são cortados na medida dos pífanos, cujo resultado de bambu rejeitado situa-se entre 10 a $20 \%$. Essa seleção visa excluir as peças de bambus que não apresentam espessura da parede e/ou comprimento do colmo adequados e/ou não são retilíneos o suficiente. A Figura 6 mostra alguns dos colmos de bambus colhidos por Lino, bem como as peças de internós selecionadas para serem produzidos os pífanos. 
Figura 6 - Colmos de bambus que Lino colheu a esquerda e peças de internós selecionados a direita
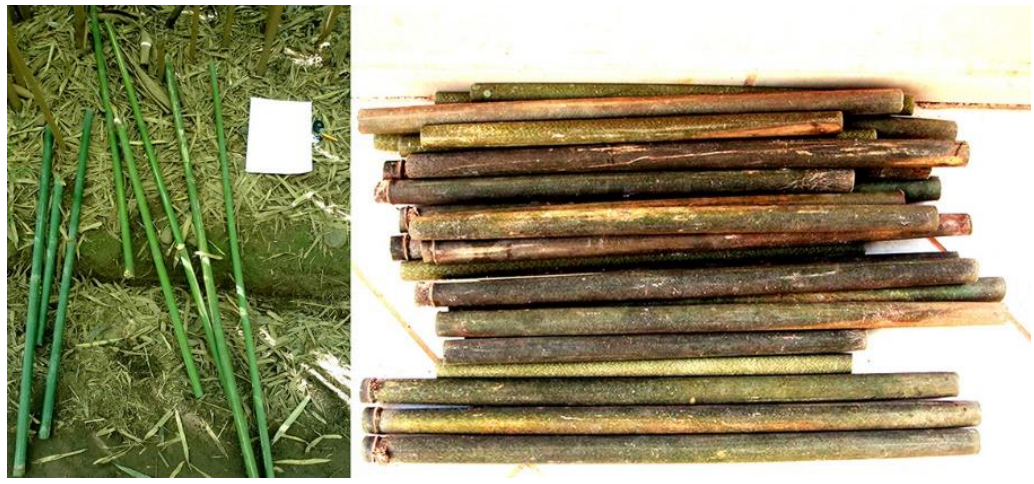

Fonte: autores.

\subsection{A Técnica de Tratamento dos Colmos de Bambus}

Depois de colhidos os colmos de bambus, feito o corte dos internós e selecionadas as partes adequadas à produção de pífanos, Lino dá o tratamento nas peças de bambu. Por ser um material biológico, o colmo de bambu quando não tratado pode ser atacado por fungos e insetos xilófagos, o que torna impreterível o seu tratamento para uma maior durabilidade de sua vida útil. Esse ataque ocorre devido a principal característica química do bambu, a presença de amido, localizado nas células parenquimáticas da planta (RUGGIERO, 2015). A conservação do bambu depende da forma de tratamento aplicado ao colmo e à finalidade de uso. Com relação a diversidade de métodos existentes para o tratamento de bambus, podem ser encontrados dois grandes grupos, os naturais e os químicos (PEREIRA \& BERALDO, 2008).

O método adotado por Lino se enquadra como natural, por meio da imersão dos colmos em água parada. Nota-se como extremamente importante neste método o cuidado com o armazenamento dos recipientes de água. É necessário vedar bem ou trocar a água regularmente, evitando a formação de criadouros de mosquitos transmissores de doenças. Nesse método de tratamento, Lino deixa os internós imersos por um período de dois meses, mas com uma troca da água a cada três dias. Desta forma, o amido de dentro dos bambus é eliminado por meio da fermentação biológica anaeróbica (ausência de ar). A Figura 7 mostra as peças de bambus durante tratamento via imersão em água parada, processo produzido e conduzido por Lino.

Figura 7 - Tratamento por imersão em água.

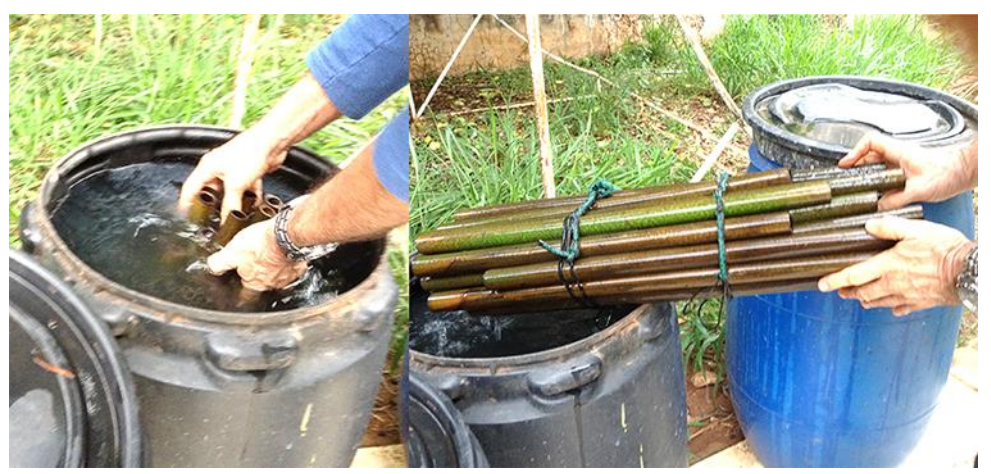

Fonte: autores. 
Depois deste processo de tratamento, com duração de aproximadamente dois meses, somam-se mais outros dois meses ou mais para que as peças de bambus tratadas estejam secas. A variação de tempo sofre influência da umidade relativa do ar, bem como da temperatura. Quando secos, os bambus ganham a coloração dourada, característica do material, e são armazenados na oficina do músico, Figura 8.

Figura 8 - Armazenamento das peças de internós de bambus tratados e secos.

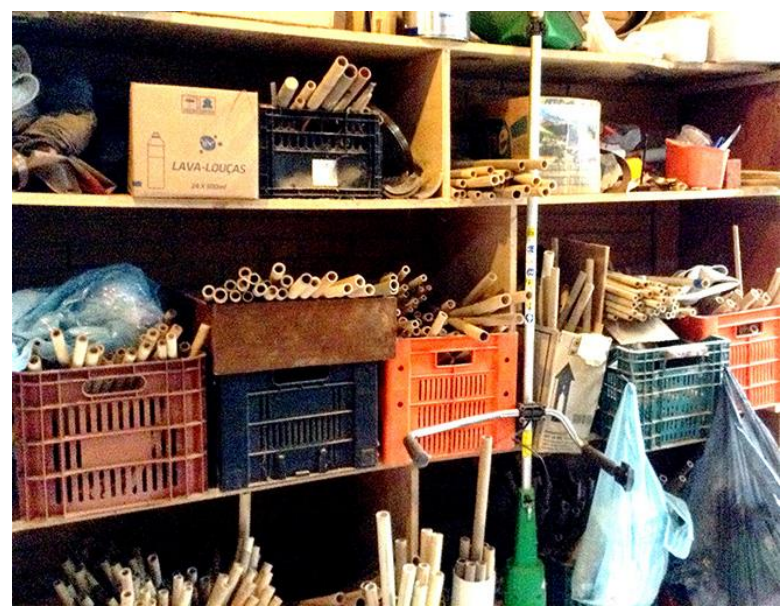

Fonte: autores.

Uma vez secas as peças de internós de bambus, Lino inicia a produção de pífanos com a lixação das paredes internas do bambu para efeito de fluidez e reverberação sonora. Em seguida, o músico e artífice insere uma rolha até a altura do diafragma ausente, resultando numa face plana necessária para boa afinação do pífano. O primeiro furo executado é o do bocal cujo centro deve ficar a uma distância de 10 a $15 \mathrm{~mm}$ da rolha conforme o tamanho do pífano. E para facilitar esse processo, Lino desenvolveu sua própria ferramenta adaptando uma barra de ferro presa a uma furadeira elétrica que rapidamente penetra no tubo da flauta. Os demais furos do instrumento, configurando cada nota da escala musical, bem como a escolha de sua relação com a tonalidade desejada pelo músico e artífice, são feitos num segundo momento.

\subsection{O Processo de Construção dos Pífanos e os Ajustes da Tonalidade Musical}

Soprando-se pelo bocal confere-se a nota resultante com o afinador eletrônico. Se for necessário corta-se a extremidade aberta para chegar à nota desejada. A partir daí inicia-se a confecção dos furos de cada nota da escala musical. Para executar a perfuração dos orifícios um a um, são usadas barras cilíndricas de ferro em brasa de diversos diâmetros iniciando pelos de diâmetro pequeno até os maiores. A escolha nessa variação de dimensão é feita em função da afinação desejada. Sucessivamente as notas são produzidas, da primeira nota da escala até o sexto furo. O resultado sonoro de cada pífano nunca é idêntico ao outro pela própria natureza heterogênea do material bambu.

O músico enfatiza que a distância entre os dois últimos orifícios necessitava de ajustes ergonômicos e foram alterados por ele para dar conforto ao dedilhado dos dedos mínimo e médio. De cada orifício é emitida uma nota musical e destampando-se os orifícios sucessivamente, obtémse uma escala maior ou diatônica na tonalidade do pífano. A nota mais grave da escala é obtida com 
todos os furos tapados. As notas mais agudas são alcançadas destapando os furos um a um. A distância entre as furações e sua relação com as tonalidades possíveis de serem alcançadas, são visíveis na Figura 9, cujos pífanos são de autoria de Lino.

Figura 9 - Relação do comprimento dos pífanos com as tonalidades

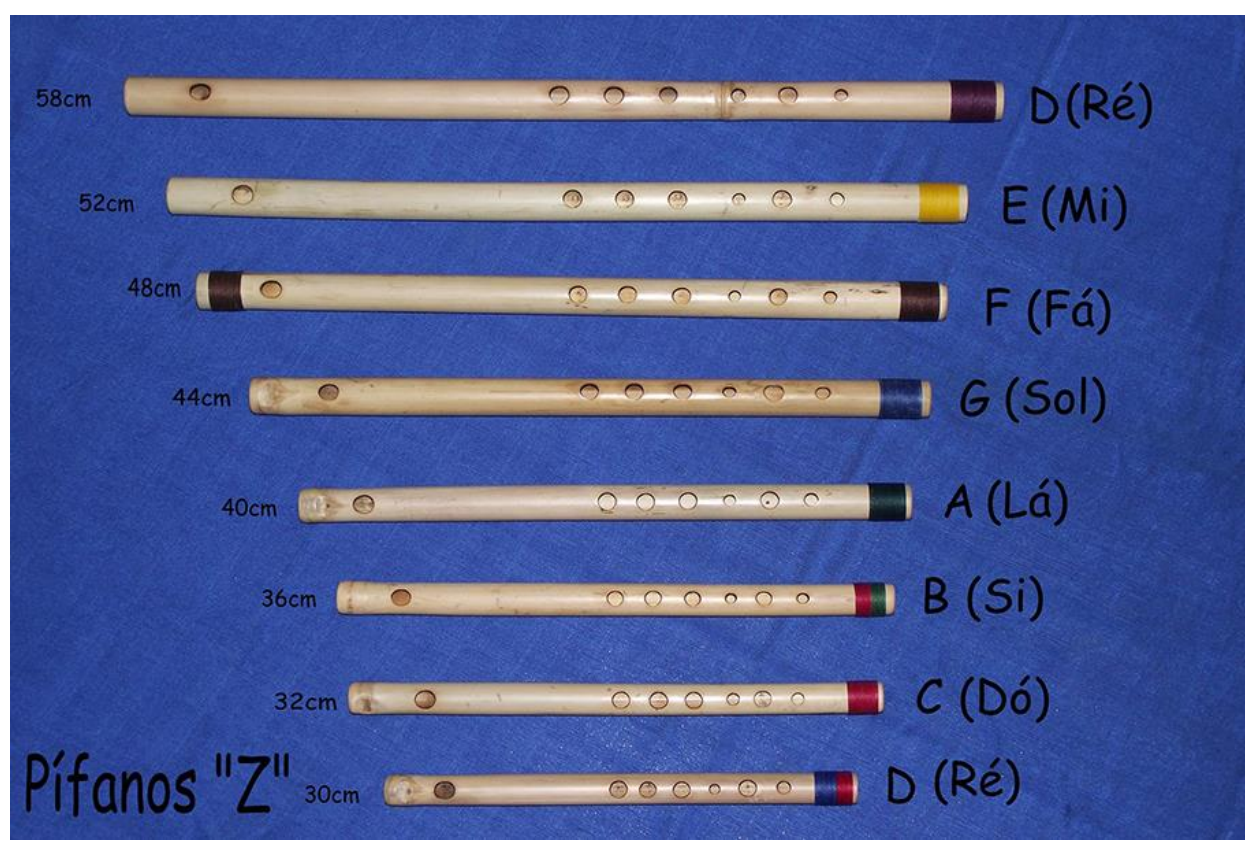

Fonte: José Cláudio Lino.

A tessitura obtida com as notas mais frequentemente realizáveis é de duas oitavas e meia. O pífano pode ser usado com outros instrumentos de afinação fixa como o piano e/ou o acordeom, entre outros. Este método de execução permite a produção de pífanos de bambu com todos os tamanhos de orifícios. Na figura 10 é possível observar que os pífanos tradicionais e aqueles produzidos por Lino têm formato semelhante e se distinguem pelos diferentes tamanhos de furos e distâncias entre eles no tubo.

Figura 10 - Pífanos de bambu com 7 orifícios.

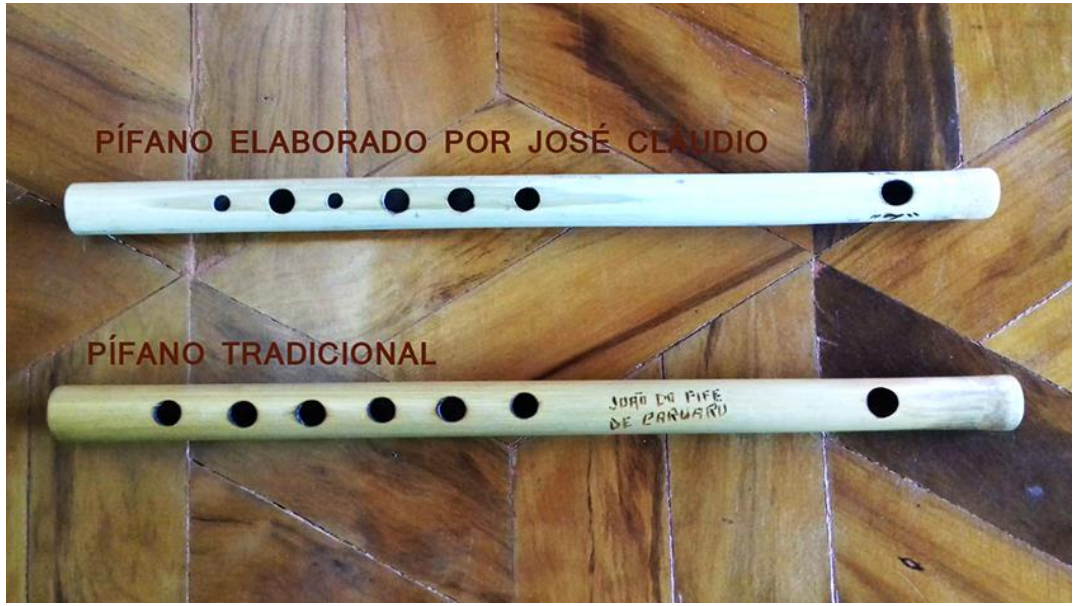

Fonte: José Cláudio Lino. 
Finalmente, quando os pífanos estão perfurados são feitos lixamentos na parte interna dos furos para a retirada do carvão resultante da perfuração a ferro quente. Também é lixada a superfície externa do pífano e, por último, uma fina camada de verniz para dar o acabamento. Lino assina com o pirógrafo os seus pífanos, utilizando a letra " $Z$ " para identificar cada instrumento com o número de fabricação e a escala referente à afinação, como mostra a Figura 11 . Atualmente, o músico e artífice relata ter alcançado a produção de dois mil pífanos de bambus.

Figura 11 - Pífano de bambu assinado e identificado por Lino.

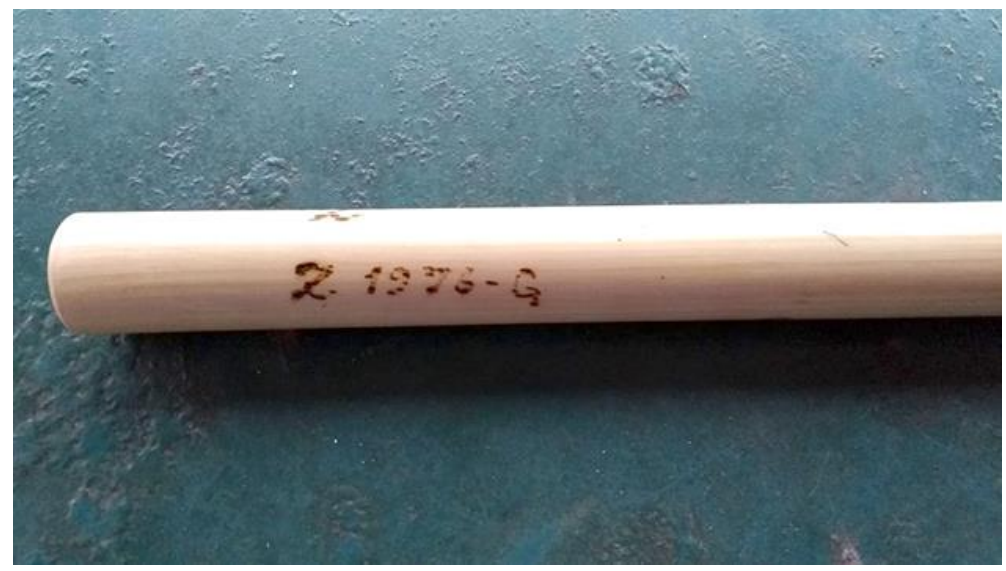

Fonte: autores.

\section{O Instrumento Musical de Bambu e sua Característica Sonora}

O instrumento musical envolve parâmetros físicos do material do qual é feito, influenciando na percepção de altura e intensidade do som produzido. As qualidades sonoras ou timbres produzidos pelo instrumento podem ser identificados pela altura que o som pode alcançar, bem como seus níveis de intensidade (LOUREIRO \& PAULA, 2006).

Lino conclui que a qualidade do instrumento que produz pode ser atribuída à sua sonoridade, sua afinação e sua ergonomia. A afinação dada aos pífanos faz com que fiquem compatíveis com outros instrumentos. Um pífano com essas características pode ser empregue em arranjos de várias vozes, como foi feito no trabalho com a Banda Bambu. Além disso, possibilita tocar gêneros mais exigentes como o Chorinho. Nesse sentido, a sonoridade do pífano de bambu se caracteriza pelo som de madeira e intensifica seus atributos melódicos e rítmicos capazes de acompanhar outros instrumentos.

O músico e construtor de pífanos de bambu tem participado de encontros nacionais de tocadores de pífanos a fim de difundir o método de escrita musical para o instrumento. Nesses encontros observou que muitas bandas têm adotado o pífano feito com material de composto vinílico PVC ou policloreto de polivinila, devido à atual escassez de bambuzais nas regiões secas do Nordeste e à falta de conhecimento sobre a utilização desta planta. A qualidade sonora específica do bambu não pode ser substituída pelo pífano de PVC, observa Lino, motivo pelo qual passou a preparar mudas de bambu, para envio por correio, aos pifeiros de diversos estados do Nordeste. 


\section{Conclusão}

O bambu está presente em grande parte das regiões brasileiras. O bambuzal integra há muitos anos o meio ambiente onde se propaga a cultura tradicional do pífano em que se realiza a prática musical e a produção do instrumento de forma coletiva e espontânea. Atualmente, esse cenário cultural está em constante mudança, devido à escassez de bambuzais na região nordeste, que vêm ocorrendo tanto por falta de manejo ou propagação de bambus quanto pela intensificação da agricultura que acaba eliminando-os.

A substituição do bambu pelos pífanos de PVC também está ligada a questão do deslocamento de um contexto cultural popular rural para o contexto urbano. A falta de acesso aos bambuzais somado às condições sociais e econômicas precárias dos tocadores tradicionais de pífanos e de grande parte de seus seguidores, leva à procura do PVC como material facilmente disponível. Os pífanos de PVC podem reproduzir as mesmas notas, melodias e ritmos, porém não tem a mesma qualidade sonora apresentada pelos pífanos de bambu. A substituição do pífano de bambu pelo PVC provoca a perda do conhecimento dos saberes sobre a manufatura tradicional do instrumento e da relação com os processos de produção ligados ao bambu. E as práticas da cultura tradicional deste instrumento modificam sua base cultural e educativa.

A importância das técnicas e métodos de ensino e aprendizagem desenvolvidos pelo músico e artífice José Cláudio Lino, assegura a difusão e disseminação deste saber. E com isso, fomenta a interlocução entre distâncias de realidades culturais e musicais. Entre músicos que recebem aprendizagem musical de prática oral e outros que têm o domínio das linguagens formais musicais com códigos da escrita. O pífano confeccionado pelo músico possibilita um intercâmbio com outros instrumentos de afinação definida, e o seu uso propicia arranjos com várias vozes. O músico e artífice investigado neste estudo explora o máximo das possibilidades do material e das qualidades técnicas oferecidas pelo bambu. A intenção coincide com um ato de fazer, ou de cumprir uma meta, do artesão e do músico artífice.

O músico constrói sentido e significações na experiência concreta de extrair a sonoridade e a música daquele objeto que executou. A possibilidade de construir um instrumento único e particular é dada pelo artífice construtor, pelo que conhece e domina. Lino o faz profissionalmente, tendo a premissa de atender às necessidades de músicos instrumentistas e à sua própria pesquisa sonora. Entretanto, seu modo de produzir não está orientado de forma a obter o máximo de lucro, adotando-se automação de procedimentos rápidos, por exemplo. Ao contrário disto, emprega o máximo de tempo e habilidade necessários para atingir o seu ponto de satisfação e exigência, além de também procurar atender o desejado pelos seus clientes. Atualmente Lino comercializa seus instrumentos por meio da internet especialmente para músicos profissionais nacionais e internacionais.

Um artesão que reproduz um modelo de instrumento musical, mas não sabe usá-lo musicalmente, se restringe ao fabrico e ao modo de produção. Comparativamente ao músico que é o artífice de seu instrumento, o artesão se priva de uma especialidade, enquanto o outro aprimora a técnica e a estética do objeto, pela busca constante das variações sonoras. Das afinações ao comprimento dos internós, dos orifícios e à seleção de espécies de bambu, entre tantas outras variabilidades. Nesse sentido, a metodologia desenvolvida por Lino na produção de um novo produto/instrumento, contribui para a aplicação desse conhecimento nos processos de aproximação entre design e artesanato, bem como a transferência de saberes técnicos e estéticos, 
a valorização da memória, da cultura artesanal, e do simbólico integrando práticas tradicionais com as práticas criativas e projetuais contemporâneas.

Por fim, é importante ressaltar a necessidade de serem produzidas pesquisas em design que permitam avançar com a construção de conhecimentos que façam a interseção com a produção artesanal de bambu. Sobretudo, dando ênfase na possibilidade do design como meio para a qualificação estética e técnica no trabalho do artesão de bambu, de forma a construir com ele novos parâmetros de valor, capazes de torná-lo, pouco a pouco, autônomo no uso dos conhecimentos trabalhados.

\section{Referências}

BRASIL. Constituição (2011). Lei no 12.484, de 08 de setembro de 2011. Institui a Política Nacional de Incentivo ao Manejo Sustentado e ao Cultivo do Bambu (PNMCB). Diário Oficial da União. Brasília, DF, 09 set. 2011. p. 01. (http://www2.camara.leg.br/legin/fed/lei/2011/lei-12484-8setembro-2011-611401-publicacaooriginal-133564-pl.html). Acesso em: 20 jul. 2017.

DOMINGUES, L. Projeto Sesc no Arraial encerra programação no Recife com João do Pife. Revista algomais, 2017. (http://www.revista.algomais.com).

FILGUEIRAS, T. S.; SANTOS-GONÇALVES, A. P. Tupi-Guarani: fonte de informações sobre bambus nativos do Brasil. Revista Heringeriana, v. 1, n. 1, p. 35-41, 2007.

FREIRE, R. D. Como será que eu afino? a relação entre sistemas de afinação e parâmetros de afinação na performance musical. Revista Música Hodie, v. 16, n.ㅇ 2, p. 232, 2016.

GRECO, T. M.; PINTO, M. M.; CAETANO, A. F. Diversity of Bamboo in Brazil. Journal of Tropical and Subtropical Botany, v. 23, n. ㅇ 1, p. 1-16, 2015.

HUNG, K.-C.; WU, J.-H. Mechanical and interfacial properties of plastic composite panels made from esterified bamboo particles. Journal of Wood Science, v. 56, p. 216-221, 2010.

KELCHNER, S. A.; BPG (Bamboo Phylogeny Group). Higher level phylogenetic relationships within the bamboos (Poaceae: Bambusoideae) based on five plastid markers. Mol Phylogenet Evol, v. 67, n.o 2, p. 404-413, 2013.

LOUREIRO, Maurício A.; PAULA, Hugo B. de. Timbre de um instrumento musical: caracterização e representação. Per Musi, n. ㅇ 14, 2006, p. 57-81.

MAGALHÃES, D. DE L. Pipiruí e Caixa de Assovio: Tocadores de pífanos e caixas nas festas de reinado. Belo Horizonte: Universidade Federal de Minas Gerais, 2009.

MAGALHÃES, D. Pesquisadores falam do pífano no Brasil. Swissinfo, 2010. (http://www.swissinfo.ch). Acesso em: 30 nov. 2017

MARGOLIN, V. Escribiendo una historia mundial del diseño: diseño y tiempo. In: Conferencia Cmd Diseno y Tiempo, 2013. (Http://imdi-cmd.blogspot.com.br/2013/09/conferencia-cmd-2013-disenoy-tiempo_2644.html)

PEREIRA, M. A. R.; BARATA, T. Q. F. Bamboo as sustainable material used in design and civil construction: species, management, characterization and applications. Key Engineering Materials, v. 634 , p. 339-350, 2015.

PEREIRA, M. A. R.; BERALDO, A. L. Bambu de corpo e alma. 1. ed. Bauru: Canal 6 Editora, 2008. 
SENNETT, R. The Craftsman. 1 edition ed. New Haven: Yale University Press, 2009.

VELHA, Cristina Eira. Significações sociais, culturais e simbólicas na trajetória da Banda de Pífanos de Caruaru e a problemática histórica do estudo da cultura de tradição oral no Brasil (1924-2006). 2009. 307 f. Dissertação (Mestrado) - Curso de História Social, Departamento de História, Universidade de São Paulo, São 2009. (http://www.teses.usp.br/teses/disponiveis/8/8138/tde-25112009-154629/pt-br.php). Acesso em: 17 jan. 2018.

WANG, X.-Q.; REN, H.-Q. Surface deterioration of moso bamboo (Phyllostachys pubescens) induced by exposure to artificial sunlight. Journal of Wood Science, v. 55, n. 1, p. 47-52, 2009. 